\section{La alteridad en el debate ético contemporáneo*}

\author{
Carlos Novoa, S. J.**
}

RECIBIDO: 14-09-16. APROBADO: 27-04-17

Resumen: Nos hallamos en la continua construcción y evolución del consenso ético mínimo universal de trascendental importancia para la humanidad. Con el presente ensayo pretendo contribuir a la edificación de tal consenso, argumentando cómo la alteridad es un mínimo ético en el que convergen la filosofía y la teología. Para ello analizaré algunas escuelas ético-filosóficas actuales relevantes (todas es imposible), la ética teológica cristiana y los aportes que cada una de estas corrientes morales hace desde su diferencia a la alteridad.

Palabras clave: Cristianismo; ética; alteridad; consenso; transformación.
Alterity in the Contemporary Ethical Debate

AвsTract: We are in the permanent construction and evolution of the universal minimal ethical consensus, a matter of transcendental importance for mankind. Through this essay, I want to contribute to the conformation of this consensus, arguing that alterity is an ethical minimum in which Philosophy and Theology come together. Therefore, I will analyze some current and important ethical philosophical schools (as analyzing all would turn out to be impossible). On the same line, I will also analyze the Christian theological ethics and the contributions that each of the mentioned schools make on behalf of alterity, taking into account their differences.

Key Words: Christianism; Ethics; Alterity; Consensus; Transformation.

\section{PARA CITAR ESTE ARTÍCULO:}

Novoa, Carlos. "La alteridad en el debate ético contemporáneo". Theologica Xaveriana 185 (2018): 1-28. https://doi. org/10.11144/javeriana.tx68-185.adec

*Artículo de reflexión que retoma un asunto central de la ética teológica-como es la urgencia de la construcción de un consenso mínimo ético universal, y los aportes del cristianismo al respecto.

** Doctor en Teología, Pontificia Universidad Javeriana Bogotá. Profesor investigador de tiempo completo de Ética y Director de Programa de Posgrados, Facultad de Teología de la misma universidad. OrCid: 0000-0002-1251-7651. Correo electrónico: cnovoa@javeriana.edu.co 


\section{Introducción}

Como verificaremos a lo largo de este escrito, el debate de la ciencia ética contemporánea es fascinante y determinante para el presente y futuro de la humanidad, pero al mismo tiempo posee un talante intrincado y complejo. Con el ánimo de contribuir a tal controversia, en el presente ensayo analizaré algunas de las escuelas morales filosóficas actuales más relevantes (todas sería imposible), la ética cristiana, la confluencia de estas en la alteridad, y sus aportes en la construcción del consenso ético mínimo universal que tanto nos urge.

La ética hace referencia al comportamiento humano personal y social desde su valoración en términos de bien y mal. He aquí entonces tres de sus elementos capitales: valoración, bien y mal. La comunidad humana siempre ha captado que se dan actitudes y comportamientos que nos dan plenitud o nos dañan, y aprehende cómo hay que optar por cultivar los primeros y desechar los segundos ${ }^{1}$. Tal es la evaluación a la que nos referimos. Ética y moral son dos términos sinónimos que vienen del griego ethos y del latín mores, mos, respectivamente, los cuales significan conducta humana personal y social. Ambos términos son usados indistintamente por notables escuelas éticas filosóficas y teológicas, y asimismo hago $\mathrm{yo}^{2}$.

La ética es la experiencia de sentido que hala toda nuestra existencia y acciones. En el mundo actual, dicha experiencia puede ser de alteridad, que nos brinda plenitud, o de egocentrismo que nos frustra y disuelve ${ }^{3}$. Este último no es una ficción ni mucho menos, sucede cuando las personas

...persiguen su interés individualista a expensas de otros conformando un estilo común de comportamiento moral negativo, o cuando hacen sufrir a sus congéneres, hallándonos de esta manera en la esfera del mal ético [...]. Todos nosotros tenemos la capacidad de ejercer el mal. ${ }^{4}$

La diferencia entre la alteridad y el egocentrismo es marcada cuando se valora de modo positivo o negativo, deseable o rechazable, bueno o malo5, y esta valoración integra el corazón de la moral. Valoramos desde el sentido, el cual creamos,

1 "El fenómeno moral consiste en la experiencia que viven todos los hombres (y que han aprendido a captar a través de la educación y de la cultura), de que algunas de las acciones que realizan repercuten en otras personas de manera particular. De hecho, vinculan a ellas la intención de querer el bien o el mal de los otros; además, lo que hacen corresponde al bien de los otros en cuanto intentan corregir lo que está equivocado" (Compagnoni, "Ética", 344-345).

${ }^{2}$ Ver a Velilla, La ética y la defensa de lo público, 729-739.

${ }^{3}$ Ver a Hernández y otros, Ética actual y profesional; Novoa, La ciencia desafía la fe; ídem, La urgencia de la ética y el derecho; Velilla, La ética y la defensa de lo público.

${ }^{4}$ Downie, "Evil, human”, 80-81.

${ }^{5}$ Bastianel, Moralità Personale nella storia, 13. 
desarrollamos y por el cual optamos, todo esto gracias a nuestro talante libre, creativo, consciente, reflexivo, trascendente y responsable.

Ser ético no es un programa que perpetua la ganancia individual, ni una exigencia de un inevitable autosacrificio. La valoración conductual no es un régimen de estricta optimización de lo útil [...] tampoco es un sistema de derechos individuales absolutos [...]. La moral es una búsqueda de toda la vida, para responder a los otros con la mejor voluntad de renunciar a todo interés egoísta. ${ }^{6}$

Valorar significa optar y asumir, o rechazar y censurar, lo que constituye la quintaesencia de la existencia humana, por lo cual la ética determina toda la vida ${ }^{7}$. A personas y comunidades, sin excepción, las constituyen dos fuerzas que se hallan en lo más hondo de su interior: la alteridad y el egocentrismo. "Yo no tengo una justificación para rechazar la ética, tampoco tengo excusas para ello. Yo no soy mentalmente incompetente. Yo no fui criada en un hogar inmoral con progenitores incompetentes. Yo simplemente hago el mal"s. Se trata de que nos enamoremos y nos dejemos llevar por la fraternidad ${ }^{9}$ rechazando el individualismo. De esta forma, la alteridad se ubica en el centro de la experiencia y la ciencia ética, y buena parte de las diversas escuelas morales actuales la asumen, como lo demuestro en las páginas que siguen.

Según nuestro sentido y su consecuente conducta construiremos una humanidad incluyente que nos realice en totalidad, u otra excluyente, en la que abunde la pobreza, el fracaso y la frustración de las grandes mayorías, generada por sectores sociales egoístas amangualados con poderes económicos y sociales opresores ${ }^{10}$. Todo esto es la ética como experiencia, la cual deviene ciencia ética, dada su gran trascendencia y urgencia de ser sistematizada para aplicarla y vivirla de la mejor manera.

La dignidad de cada persona humana y el bien común son cuestiones que deberían estructurar toda política económica, pero a veces parecen solo apéndices agregados desde fuera para completar un discurso político sin perspectivas ni programas de desarrollo integral. ¡Cuántas palabras se han vuelto molestas para este sistema! Molesta que se hable de ética, molesta que se hable de solidaridad mundial,

\footnotetext{
${ }^{6}$ Allen, The New Ethics, 7. La traducción del inglés es mía.

7 "La ética es asunto de todos los ciudadanos, pues trata de los valores que rigen nuestra forma de vida, de lo bueno y lo malo, no menos que de la diversidad de planteamientos globales de la existencia plasmados en diferentes culturas" (Singer, Compendio de ética, contraportada).

${ }^{8}$ Allen, The New Ethics, 12. La traducción del inglés es mía.

${ }^{9}$ Junges, Evento Cristo e açāo humana. Temas fundamentais da ética teológica, 357.

${ }^{10}$ Ver a Velilla, La ética y la defensa de lo público.
} 
molesta que se hable de distribución de los bienes, molesta que se hable de preservar las fuentes de trabajo, molesta que se hable de la dignidad de los débiles ${ }^{11}$.

\section{Escuelas ético-filosóficas}

Las escuelas ético-filosóficas que analizaré son la teoría de la acción comunicativa, la posmodernidad, el pragmatismo, la alteridad, la de Emanuel Kant, y la analítica.

\section{La acción comunicativa: entre todos construimos la ética}

La teoría de la acción comunicativa ${ }^{12} \mathrm{o}$ ética discursiva verifica la necesidad de la constitución de consensos en la elaboración de cualquier camino humano. Acá por consenso no se entiende suma de votos o conformaciones mayoritarias de cualquier manera, sino ante todo la dialéctica entre las diversas corrientes valorativas comportamentales para hallar puntos compartidos que hagan posible la convivencia humana universal y la solución a gravísimos problemas que nos tocan a todas las personas sobre la tierra, los cuales solo podemos abocar de manera conjunta; por ejemplo, la guerra, las graves injusticias del comercio internacional, las más diversas discriminaciones (mujeres, pobres, extranjeros, ancianos, niños, homosexuales y otros), el desastre ecológico, la sostenibilidad y la vigencia del derecho internacional.

Se trata de la construcción de un mínimo que acatemos toda la humanidad, en el que al mismo tiempo cada grupo humano pueda mantener sus propios modelos morales. No es posible unificar a todas las mujeres y hombres en uno de estos modelos específicos. En este sentido se manifiesta el papa Francisco en una entrevista a Eugenio Scalfari ${ }^{13}$.

$\mathrm{Al}$ interior de la ética discursiva y otras escuelas de la ciencia ética creemos que la "Declaración universal de los derechos humanos personales y sociales" de 1948 es un buen primer consenso ético mínimo mundial que deberá evolucionar con el correr de los tiempos, las culturas y las sociedades. En este desenvolvimiento la acción comunicativa le apuesta a la centralidad de la persona, del otro y a su plena e integral realización como el norte último de todo su concurso. Al hablar del otro hablamos de otreidad o alteridad, del latín alter, que significa otro.

\footnotetext{
${ }^{11}$ Francisco, "Exhortación apostólica Evangelii gaudium sobre el anuncio del Evangelio en el mundo actual" 203. Para una visión panorámica introductoria sobre la ciencia ética sugiero ver a Küng, Ética mundial. Una guía para descubrir los valores que todos tenemos en común; Savater, Ética para Amador; Novoa, La urgencia de la ética y el derecho.

${ }^{12}$ Ver a Apel, Paradigmas de filosofía primera; a Cortina, Ética minima. Introducción a la filosofía práctica; y a Habermas, Teoría de la acción comunicativa.

${ }^{13}$ Francisco, "Entrevista del Papa con Scalfari”.
} 
Se trata de la relación interpersonal y social en desinterés, que busca el bien de todos, la plena realización de las propias capacidades y posibilidades, o sea la comunicación = comunión $=$ unión común. $Y$ toda comunicación es discursiva: por eso también hablamos de la ética discursiva o de discurso. Discurso viene del latín discürsus; este proviene de dis y cürro, que significan de un lado para otro y correr ${ }^{14}$. Entonces discursear es desplazarse, lo opuesto a estático, y la comunicación humana es un continuo moverse recíprocamente en relación con lo diverso, lo desconocido, lo que nos sorprende y enriquece: el otro. Se trata de un desplazamiento de la pluralidad humana para consolidar el mínimo común requerido en el fomento de la diversidad; de un movimiento que debe acaecer al interior de las más variadas culturas, ciencias, nacionalidades, religiones e ideologías.

En este contexto, la ética discursiva se pregunta por el criterio último de objetividad y validez de la moral, para hallar la siguiente contestación:

...la explicación se encuentra en la realidad misma del acuerdo o del consenso que es el fundamento de toda ley nacida de una sociedad democrática ¿¿De dónde sale el imperativo que obliga a los individuos a buscar el convenio y asumirlo? se pregunta, concretamente Apel. La respuesta es que la búsqueda o aceptación del acuerdo es una consecuencia de algo que nos constituye: el $a$ priori de la comunicación. ${ }^{15}$

Desde este horizonte comunicacional, para Jürgen Habermas, hoy la mayor urgencia de la convivencia humana es "la conciencia de lo que falta, de lo que clama al cielo: la solidaridad, en especial con las miríadas de pobres y excluidos de este mundo", según lo formula en su último libro ${ }^{16}$.

\section{La alteridad: el reconocimiento del otro}

La alteridad constata el bien por excelencia en el encuentro generoso, gratuito y en reconocimiento mutuo con el otro. De esta manera garantizamos la plena realización de todas nuestras capacidades a nivel personal y social ${ }^{17}$. En esta vivencia captamos

\footnotetext{
${ }^{14}$ Coromines, Breve diccionario etimológico de la lengua castellana, 152, 195.

${ }^{15}$ Camps, Concepciones de la ética, 23. La acción comunicativa es "el medio lingüístico, mediante el que se concatenan las interacciones y se estructuran las formas de vida, el que hace posible a la razón comunicativa. Esta racionalidad inscrita en el telos que representa el entendimiento intersubjetivo y constituye un esemble de condiciones posibilitantes" (Habermas, Facticidad y validez, 65).

${ }^{16}$ Ídem, Carta al Papa (La conciencia de lo que falta), 217, 218, 64, 65, 222, 223.

${ }^{17}$ Respecto de la filosofía de la alteridad, ver a Benedicto XVI, "Encíclica Caritas in veritate sobre el desarrollo humano integral en la caridad y en la verdad", a Francisco, "Exhortación apostólica Evangelii gaudium"; a Lévinas, El tiempo y el otro; y a Zubiri, Sobre el hombre.
} 
que, en el interior de todo ser humano, existe un hondo impulso a realizar la otreidad. Elocuentes textos del papa Francisco sintetizan de forma cuestionadora, accesible y profunda esta fascinante experiencia del otro ${ }^{18}$.

"En la praxis de la alteridad un paso simple pero crucial separa el egoísmo de una teoría moral mínimamente aceptable y consistente: el reconocimiento de los otros como mucho más que meros instrumentos de mi realización” ${ }^{19}$. Es válido que yo promueva mis propios intereses y mi realización personal, siempre y cuando esto no implique la negación del proceso de realización de los demás. Por ende, las otras personas conforman un límite para mi conducta. Evidentemente, el camino de la otreidad me conduce a buscar el bien de mis congéneres. En este ámbito, mujeres y hombres se empeñan en la construcción de lo mejor para sus congéneres, no solo para sí. Por ello reconocen a los otros, más allá del pequeño círculo de sus amigos, como radicalmente iguales; y yo no puedo exigir privilegios especiales simplemente por ser la persona que soy ${ }^{20}$.

La alteridad coincide con la ética del cuidado o la dedicación, la cual nos enriquece sobremanera. Por eso paso a referirme a ella. Esta filosofía moral contemporánea nace en los Estados Unidos, y cuenta entre sus mentores a los intelectuales William Frankena, Carol Gilligan y a la reconocida filósofa Nel Noddings ${ }^{21}$. Para esta visión ética, las relaciones humanas deben asegurar responsabilidad mutua, cuidado recíproco y confianza. Asimismo, cuando la gente requiere cuidado especial, debemos suspender temporalmente nuestros proyectos, poner a un lado la propia agenda y asegurar a priori la respuesta que se nos solicita. Actuamos de esta manera aprehendiendo la realidad del otro en sus propios términos.

Por consiguiente, el cuidado debe ser la actitud central y el método de la ética. La dedicación es mucho más que un imperativo moral, debe permear toda conducta y virtud. Nos empeñamos en el bienestar de todos y en el ejercicio de la justicia. ${ }^{22}$

\footnotetext{
${ }^{18}$ Francisco, "Audiencia general, Roma, 5 de junio de 2013"; ídem, "Exhortación apostólica Evangelii gaudium"; ídem, Discurso a los participantes en el Encuentro Mundial de Movimientos Populares, 28 de octubre de 2014"; ídem, "II Encuentro Mundial de los Movimientos Populares con el papa Francisco, Santa Cruz de la Sierra, Bolivia, 7-9 de julio de 2015"; ídem, "Homilía en Lampedusa. Campo de deportes, 8 de julio de 2013".

${ }^{19}$ Hepburn, "Egoism and Altruism”, 236-237. La traducción del inglés es mía.

${ }^{20}$ Ibíd., 236-237.

${ }^{21}$ Ver a Noddings, Caring: A Feminine Approach to Ethics \& Moral Education.

${ }^{22}$ Allen, The New Ethics, 5. La traducción del inglés es mía.
} 
El respeto mutuo debe caracterizar todo vínculo humano. El cuidado realiza con gran relevancia ética nuestro interés por cada ser humano, más allá de las necesidades apremiantes o la urgencia por sobrevivir ${ }^{23}$.

\section{La posmodernidad: el fin de la metafísica y la razón instrumental deificada}

La posmodernidad ${ }^{24}$ certifica el fin de la hegemonía de los metarrelatos (los vacíos ideales absolutos) y la razón instrumental, para verificar el fracaso del imperio de la Modernidad. En este sentido reivindica la vivencia de lo cotidiano, lo vital, el afecto, la existencia, el placer y lo estético ${ }^{25}$. Para la posmodernidad -al decir de Gianni Vattimo, exímio exponente de esta escuela, y de Richard Rorty, pragmatista y posmoderno-, el único absoluto posible es nuestra referencia al otro, el congénere, en otras palabras, la alteridad ${ }^{26}$.

El filósofo italiano Gianni Vattimo formula la posmodernidad filosófica con acierto: en ella lo importante no son los hechos sino sus interpretaciones. De la misma forma que el tiempo se halla determinado por la posición relativa del observador, la validez de un acaecer no es más que una realidad que solo puede abocarse con una interpretación relativa y por lo mismo incierta. El patrón determinista de la causalidad, de la verdad de un sujeto fuerte al estilo de Hegel, Kant o Marx, y la perspectiva del tiempo lineal -como la de Leibniz-son cuestionados en profundidad.

El ser no está escrito en ninguna parte de una especie de estructura del lenguaje chomskiana, más históricamente condicionada, sino que es justamente el resultado del diálogo humano. Eso me parece muy cercano al dictum evangélico cristiano que afirma: "Cuando dos o más estén reunidos en mi nombre yo estaré con ellos". Por tanto es justamente allí donde Dios está presente; Jesús dice incluso que cuando ves a un pobre en la esquina de la calle, Dios está ahí y no en ningún otro sitio. [...]. En suma, el cristianismo [...] nos ha liberado de la importancia de la ontología objetiva y también de la importancia de cualquier tipo de fundamento que no esté relacionado con el amor y la solidaridad. ${ }^{27}$

\footnotetext{
${ }^{23}$ Ver a Allen, The New Ethics, 4 a 7.

${ }^{24}$ Ver a Vattimo, Adiós a la verdad; ídem, Creer que se cree; y a Lyotard, La condición posmoderna. Informe sobre el saber.

${ }^{25}$ Ibíd.

${ }^{26}$ Ver a Rorty, Una ética para laicos; y a Rorty y Vattimo, El futuro de la religión.

${ }^{27}$ Ibíd., 102, 103. Ver a Vattimo, Adiós a la verdad. "Gilles Deleuze apunta al corazón de la posmodernidad cuando verifica que en esta la ética no se circunscribe a los campos de los derechos, la justicia distributiva y la ley. Acá la moral tiene mucho más que ver con la construcción de la política, la libertad y el manejo del poder y sus relaciones. En este contexto los asuntos de la responsabilidad se abocan en términos de alteridad y relaciones interpersonales" (Braidotti, “Nomadic Ethics”, 173. La traducción del inglés es mía).
} 
La posmodernidad en su pluralidad no conduce a una ética sin valores morales; su fuerte ascendencia acaece en el actual relativismo cultural y en la verificación de la imposibilidad de señalar algo cómo definitivamente bueno o malo. La moral posmoderna pone en tela de juicio el cinismo religioso muy presente en Occidente, y subraya una ética basada en la intencionalidad de los actos y la comprensión inter y transcultural de corte secular de los mismos ${ }^{28}$.

En términos filosóficos la posmodernidad comparte una cierta crítica a los valores de la Ilustración y las exigencias de verdad formuladas por los pensadores comunitaristas-liberales. También comulga con el neopragmatismo al estilo de Richard Rorty quien acoge el fin del papel de la presunción filosófica como un discurso privilegiado de verdad..$^{29}$

En esta óptica, la posmodernidad podría verse como un desenvolvimiento del denominado "giro lingüístico" que viene haciendo presencia en el pensamiento filosófico. Este giro es de particular relevancia, ya que formula el carácter constructivo y semántico de todo tipo de conocimiento, incluido el ético, al argumentar de esta forma con solidez la superación del iusnaturalismo, el cual entorpece con mucho la conducta humana ${ }^{30}$.

En la representación (gnoseológica) están dados solo objetos: los estados de cosas o los hechos los aprehendemos en pensamientos. Con esta crítica da Frege el primer paso hacia el giro lingüístico. Pensamientos y estados de cosas ya no pueden, sin más mediaciones, quedar alojados en el mundo de los objetos representables; solo son accesibles en tanto que expuestos, es decir, en tanto que estados de cosas expresados en oraciones. ${ }^{31}$

La ética posmoderna enfatiza el fin de todo arquetipo dado e impuesto desde fuera a la existencia y cotidianidad humanas, al insistir en que su bondad y maldad se construyen en el devenir dialógico y de reconocimiento mutuo. Esto es de capital importancia porque en la historia humana hemos vivido grandes frustraciones, por causa de parámetros conductuales dominantes totalmente carentes de la libertad y creatividad que nos constituyen como personas; hegemónicos ${ }^{32}$ como el imperio de

\footnotetext{
${ }^{28}$ Para los dos últimos párrafos, ver a Jozami "Filosofía posmoderna".

${ }^{29}$ Norris, “Post-modernism”, 745. La traducción del inglés es mía.

${ }^{30}$ Para este párrafo, ver ibíd.

${ }^{31}$ Habermas, Facticidad y validez, 73.

32 "Para la posmodernidad la única e irrepetible poesía de la vida es personal y no viene de una 'esencia natural', sino de su particularidad específica procedente de los complejos discursos en que se halla [...]. La posmodernidad no habla del fin del sentido y de los valores éticos sino del término de ciertas hegemonías como el iusnaturalismo" (Deeds, "Postmodernism and Political Philosophy" en Routledge, Routledge Encyclopedia of Philosophy, Vol 7, 589-590. La traducción del inglés es mía). Ver a Braidotti, "Nomadic Ethics", 170-196.
} 
la razón instrumental en la idolización del dinero y del $\operatorname{poder}^{33}$ que padecemos en el mundo de hoy, donde la persona y la comunidad no tienen ningún valor, sino que solo se les manipula e instrumentaliza para el ejercicio de tal idolización.

Ontología significa que queremos hablar del ser, pero el ser no es otra cosa que el logos interpretado como diálogo, el Gespräch, que se da como la conversación que se desenvuelve efectivamente entre las personas. La realidad, de este modo, conserva todavía un significado para Heidegger, pero es solo el resultado del diálogo histórico entre las personas; nosotros no estamos de acuerdo porque hayamos encontrado la esencia verdadera de la realidad, sino que decimos que hemos encontrado la verdadera esencia de la realidad cuando nos ponemos de acuerdo. ${ }^{34}$

\section{El pragmatismo: por sus hechos los conocerán}

El pragmatismo ${ }^{35}$ reivindica que las conductas son el único criterio ético de validez. Como ya hemos señalado, Richard Rorty, gran exponente de esta filosofía, apela al otro como el referencial capital:

Pienso que la respuesta a la cuestión “¿dónde reside nuestro deber hoy?" es: "Nuestro único deber es hacia nuestros conciudadanos". Se puede entender como ciudadano a los otros italianos, a los otros europeos o a los otros humanos. Pero sea cual sea el límite que uno tenga en su sentido de responsabilidad, este sentido de responsabilidad cívica es posible. ${ }^{36}$

Desde [mi] perspectiva relativista nunca hubo ni habrá una verdad más grande que nosotros [...] una visión de progreso horizontal hacia un amor cooperativo común a escala planetaria. ${ }^{37}$

33 "La Posmodernidad cuando, por ejemplo, Paul Feyerabend reclama la separación entre la ciencia y el Estado, cuestiona justamente la confusión de las razones, la razón de Estado y la razón de ser. Son inconmensurables la una con respecto a la otra en la medida en que la primera es inconmensurable respecto de la 'razón de ser', que llamamos también [...] la ética, y que puede incitar a un ciudadano a preferir la muerte a vivir como nazi [...]. La confusión de las razones carece de excusa razonable. Se apoya en el proyecto 'muy moderno' de una lengua universal, es decir, en el proyecto de un metalenguaje capaz de recoger sin dejar restos todas las significaciones establecidas por los lenguajes particulares. Esta duda arrojada sobre 'la razón' no viene de las ciencias sino de la crítica del metalenguaje, es decir, de la decadencia de la metafísica (y, por lo tanto, de la decadencia de la metapolítica)" (Lyotard, La Posmodernidad, 76-77). ${ }^{34}$ Rorty y Vattimo, El futuro de la religión, 88-89.

${ }^{35}$ Ver a Pierce, Pragmatism as a Principle and Method of Right Thinking. The 1903 Harvard Lectures on Pragmatism; James, Pragmatism: A New Name for Some Old Ways of Thinking; Rorty, Filosofia y futuro; Rorty y Habermas, Sobre la verdad: ¿validez universal o justificación? Rorty, Una ética para laicos.

${ }^{36}$ Rorty y Vattrimo, El futuro de la religión, 110. "Lo que ahora estamos viendo es que en ausencia de un gobierno mundial (en ausencia de una autoridad global que pueda poner el capitalismo global al servicio de la democracia) vuelven a emerger los peores rasgos del capitalismo" (ibíd., 115).

${ }^{37}$ Rorty, Una ética para laicos, 29. 
Pragmatismo es un término de etimología griega: pragma (acción). Se trata de una corriente filosófica estadounidense, que emerge como rechazo al positivismo, a finales del siglo XIX, promovida por Ch. S. Pierce y William James, entre otros, quienes la desarrollaron en diversos horizontes. En general, el pragmatismo cree que el sentido de un enunciado lo constituye sus implicaciones en el porvenir, por lo que los objetos han de ser plasmados respecto de las consecuencias prácticas que producen, o que se anhelan generar en el tiempo venidero. En William James, el pragmatismo logra también una cristalización en el ámbito moral ${ }^{38}$.

La idea característica del pragmatismo filosófico es la eficacia en la aplicación práctica, cómo resolver algo más efectivamente en la praxis. Esta idea provee un parámetro para la determinación de la validez de un discurso, la rectitud de las conductas, o el valor de las apreciaciones. ${ }^{39}$

Con Emanuel Kant el pragmatismo insiste en que realicemos lo suficiente, ya que nuestros limitados esfuerzos y búsquedas humanas no pueden nunca alcanzar la totalidad. Desde esta óptica se trata de un asunto más funcional que especulativo, en el que priorizar los motivos prácticos sobre los teóricos es un insoslayable hecho de la condición humana ${ }^{40}$.

Es cierto que la ética trata del bien y del mal; pero la cuestión fundamental es otra: ¿Cuál es mi fin? ¿Para qué existo? (Collected Papers of Charles Sanders Pierce, Volumen 2, párrafo 198). Con otras palabras, el problema fundamental de la ética consiste en determinar el fin de la conducta, entendiéndose por conducta la acción deliberada y sometida a autocontrol. El concepto del bien es, pues, básico en la ética de Pierce.

[...]. Por otra parte, el pragmatismo exige que el concepto del fin pueda explicarse con base en las consecuencias prácticas ya concebidas, en proposiciones condicionales que se refieran a la conducta deliberada o controlada. De aquí no se deduce, sin embargo, que el pragmatista sea en ética defensor de la acción por la acción misma. Porque, como hemos visto, la acción deliberada o racional -este es el objeto de la ética-va dirigida a la realización de un fin ideal. ${ }^{41}$

John Dewey, filósofo estadounidense y uno de los fundadores del pragmatismo, para evitar cualquier equívoco prefería dar el nombre de instrumentalismo a su

\footnotetext{
${ }^{38}$ Para este párrafo, ver Ferrater Mora, "Pragmatismo", III, 2872.

${ }^{39}$ Rescher, "Pragmatism", 747. La traducción del inglés es mía. "El pragmatismo desarrolla una autoconsciencia histórica del ser humano como quien tiene la capacidad de llegar a ser ciudadano de una sociedad democrática liberal, una comunidad que constantemente busca ubicarse más allá de sus propios límites, teniendo como mira la implementación de la inclusión social para los excluidos y marginados" (Rorty, "Pragmatism", Vol. 7, 638. La traducción del inglés es mía).

${ }^{40}$ Para este párrafo, ver ibíd.

${ }^{41}$ Copleston, Historia de la filosofía, Tomo 8, 308-309. Ver a Pihlström, "Peirce's Place in the Pragmatist Tradition", 27-57.
} 
filosofía. "Para él la esencia del instrumentalismo pragmático se halla en concebir el conocimiento y la conducta humana como medios para asegurar en la existencia experimentada los bienes, es decir, las cosas excelentes de cualquier especie (ver a Dewey, The Quest for Certainty, 1929, p. 37)". ${ }^{42}$ En este sentido Dewey estaba de acuerdo con el experimentalismo de Peirce, ya que estaba convencido de que la probación determina toda proposición garantizada.

En este horizonte, las acciones y los deseos humanos condicionan todo tipo de verdad, incluso la científica. Por tanto, no es legítimo negarse a creer en doctrinas que ejercen una acción benéfica sobre la vida de las personas, por el hecho de que estas no se basen en pruebas racionales suficientes. En casos como estos -afirmaba Jameses necesario correr el riesgo de creer ${ }^{43}$. Por ello James termina en el teísmo y las doctrinas espirituales tradicionales, argumentando que ellas son útiles a la conducta y benéficas a la vida humana ${ }^{44}$.

\section{Emanuel Kant: el absoluto de la dignidad humana}

"El imperativo práctico será así pues el siguiente: obra de tal modo que uses la humanidad tanto en tu persona como en la persona de cualquier otro siempre a la vez como fin, nunca meramente como medio" ${ }^{45}$. He aquí el meollo del imperativo categórico, quintaesencia de la ética de Kant. La favorabilidad universal y la alteridad se imponen de nuevo, como lo venimos verificando en otras escuelas éticas contemporáneas. El pensador de Köenisberg llega a esta trascendental conclusión, contemplada actualmente por la mayoría de escuelas de la ciencia ética, lo cual marca el gran influjo kantiano en la ciencia moral actual ${ }^{46}$.

Para Kant, esta trascendental conclusión emerge al analizar el comportamiento cotidiano de los humanos y constatar que, en muchos casos, estos tienen como criterio fundamental el logro de satisfacciones sensibles egoístas:

De hecho encontramos también que cuanto más se ocupa una razón cultivada con el propósito dirigido al disfrute de la vida y de la felicidad, tanto más se

\footnotetext{
${ }^{42}$ Abbagnano, Dizionario di filosofia, 848. La traducción del italiano es mía.

43 "En la perspectiva de Peirce la teoría debe distinguirse de la práctica y la filosofía no puede ayudarnos en 'asuntos de vital importancia'. Peirce piensa que los asuntos existencialmente importantes tienen que ser resueltos por el instinto y el sentimiento más que por una mera reflexión intelectual o teórica" "Peirce’s Place in the Pragmatist Tradition”, 40, 41. La traducción del inglés es mía.

${ }^{44}$ Para los dos últimos párrafos ver a Abbagnano, Dizionario di filosofia, 848-849; ver a Tiles, "Pragmatism in Ethics" 7, 640-644.

${ }^{45}$ Kant, Fundamentación de la metafísica de las costumbres, 189.

${ }^{46}$ Camps, Guariglia y Salmerón, Concepciones de la ética, 19-27; ver a O’Neill, “Kantian Ethics" 5 , 200-204.
} 
aleja el hombre de la verdadera satisfacción, de lo cual surge en muchos, y por cierto en los más experimentados en el uso de la misma (razón), con solo que sean lo bastante sinceros para confesarlo, un cierto grado de misología, esto es, odio a la razón, porque tras el cálculo de todo el provecho que sacan, no digo de la invención en todas las artes del lujo ordinario, sino incluso de las ciencias (que al cabo les parecen ser también un lujo del entendimiento), encuentran sin embargo que en realidad se han echado encima más trabajos que felicidad hayan ganado, y terminan por envidiar más bien que despreciar al tipo más ordinario de hombre, que está más cerca de la dirección del mero instinto natural y no concede a su razón mucho influjo sobre su conducta. ${ }^{47}$

Es obvio que este criterio comportamental afecta negativamente a las demás personas, por lo cual Kant investiga la conformación de este criterio y garantiza la realización positiva de todas las mujeres y hombres al hallarlo en la persona misma. Nuestro filósofo alemán llega a esta conclusión teniendo como criterio aquel parámetro ajeno a toda inclinación sensible y egoísmo (para Kant estos dos son concomitantes), lo que él encuentra por medio de la pura razón ${ }^{48}$.

El referencial absoluto de la persona, de su dignidad, es actualmente indiscutible. Por desgracia, Kant no logró percibir que no hay que eliminar la sensibilidad (inclinaciones) y la pasión para llegar a él ${ }^{49}$, ya que la solidaridad es la más sentida de todas las pasiones, al garantizar el ejercicio estético humano, que es insoslayable en su talante. La contribución de Kant a la filosofía moral fue desarrollar con gran complejidad la tesis de que los juicios morales son expresiones de la razón de tipo práctico. Para Kant la razón práctica o la "voluntad racional" no deriva sus principios de la acción, por ejemplo, de los sentidos o de la razón teórica pura, sino que los encuentra dentro de su propia estructura racional.

La habilidad para usar la razón práctica con el fin de generar principios conductuales, es denominada por el maestro de Köenisberg "la autonomía de

\footnotetext{
${ }^{47}$ Kant, Fundamentación de la metafisica de las costumbres, 121. "Por amor a los hombres voy a admitir que la mayor parte de nuestras acciones son conformes al deber; pero si se miran de cerca los pensamientos y los esfuerzos se tropieza uno por todas partes con el amado yo que continuamente se destaca y sobre el que se fundamentan los propósitos, y no sobre el estrecho mandamiento del deber, que muchas veces exigiría la renuncia y el sacrificio" (ibíd., 145).

${ }^{48}$ Para el desarrollo de esta argumentación, ver íbid, "Kant argumenta cómo la razón humana es una fuente autónoma de principios conductuales, inmune a las lisonjas de las inclinaciones sensuales. Esta razón determina el valor ético y la decisión comportamental, siendo la autonomía humana la más alta valía moral y la condición de posibilidad de todos los demás valores éticos" (Guyer, "Kant Immanuel" 5, 189). La traducción del inglés es mía.

${ }^{49}$ Kant, Fundamentación de la metafísica de las costumbres, 121. "Pero las inclinaciones mismas como fuentes de las necesidades están tan lejos de tener un valor absoluto para desearlas a ellas mismas que más bien estar enteramente libre de ellas tiene que ser el deseo universal de todo ser racional" (ibíd., 187).
} 
la voluntad", la cual aprehende como el constituyente de la dignidad de la persona. ${ }^{50}$

El filósofo del imperativo categórico argumenta cómo en virtud de sus voluntades autónomas las personas tienen dignidad o son "fines en sí mismas". Combinando este aspecto de la voluntad autónoma con la idea de la universalidad, Kant formula el ideal del reino de los fines en sí mismos, o de los pueblos respetándose mutuamente sus voluntades universalizadoras. ${ }^{51}$

Este ideal viene teniendo desde entonces enorme influencia en el panorama de la ciencia ética, de la cual su más distinguido y reciente exponente es John Rawls, quien acepta el planteamiento capital kantiano del mutuo respeto entre las voluntades autónomas racionales, y añade sus propios aportes para constituir las bases de la teoría de la justicia ${ }^{52}$.

Pues los seres racionales están todos bajo la ley de que cada uno de los mismos debe tratarse a sí mismo y a todos los demás nunca meramente como medio, sino siempre a la vez como fin en sí mismo. De este modo, surge un enlace sistemático de seres racionales por leyes objetivas comunes, esto es, un reino, el cual, dado que estas leyes tienen por propósito precisamente la referencia de estos seres unos a otros como fines y medios, puede llamarse un reino de los fines (desde luego, solo un ideal). ${ }^{53}$

Así, Kant se anticipa doscientos años al gran consenso mínimo universal de la "Declaración universal de los derechos humanos" de 1948. Esta se basa en la asunción, por todos los pueblos, de los tres valores éticos absolutos de la dignidad humana y sus correlatos de solidaridad y justicia. Por ello, en tal Declaración, la humanidad se compromete a hacer efectivos para todas las mujeres y los hombres, sin exclusión, tales valores, es decir, el reino o la comunidad de los fines, la cristalización real de los tres absolutos mencionados, acción comunicativa y mínimo ético universal efectivos, y alteridad por antonomasia ${ }^{54}$.

\section{La filosofía analítica o del lenguaje: las personas somos palabra}

Las denominaciones "análisis", "analítica" o "análisis lógico" se refieren a una amplia corriente filosófica de carácter antimetafísico, si se entiende por metafísica la pretensión

\footnotetext{
${ }^{50}$ Downie, "Kantian Ethics", 470. La traducción del inglés es mía.

${ }^{51}$ Ibíd.

52 Para los dos últimos párrafos, ver ibíd.

${ }^{53}$ Kant, Fundamentación de la metafisica de las costumbres, 197.

${ }^{54}$ Ver la "Declaración universal de los derechos humanos personales y sociales" de 1948.
} 
de encajonar la totalidad de la existencia en esencias inmutables y vigentes, ayer, hoy y siempre, en todo lugar y circunstancia. Con Kant y todo el pensamiento posterior, esta pretensión esencialista cae como un castillo de naipes al verificarse que la gnoseología y la ética no están dadas, sino que son un constructo personal y social en continuo devenir.

Constituyen dicha corriente sectores que desarrollan la lógica simbólica y la semiótica, que rechazan la neutralidad de cualquier tipo y buscan estructurar una cierta idea de la actividad filosófica. La analítica censura el talante puramente especulativo de la ciencia de la sabiduría, la cual abocan como quehacer crítico y reflexivo. No creen que la filosofía tenga un objeto propio, al considerar que su papel es el estudio de las proposiciones ${ }^{55}$ para hallar si tienen o no significación: si se conforman como normas lógicas o lingüísticas, formulaciones sobre hechos o puras manifestaciones de sentimientos ${ }^{56}$.

La escuela analítica o del lenguaje ${ }^{57}$ certifica que las personas somos comunicación, lenguaje y palabra, y que solo en la común-unión = comunicación podemos existir, ya que como individuos absolutamente aislados morimos indefectiblemente. Por ende, toda praxis humana es lenguaje y en este se construye y cristaliza. El ejercicio del lenguaje que realiza y no niega lo humano solo deviene en la alteridad. Varias corrientes de la analítica contemporánea verifican como ya superado el supuesto fundamental en que se funda la filosofía analítica y la filosofía del lenguaje en general:

...esto es, el carácter representacional del lenguaje mismo, como si este fuera en sustancia un esquema de lo que es el mundo, y que determina que la principal cuestión filosófico-lingüística sea la relación del lenguaje con el mundo: el significado. Así desaparecen [...] por la fuerza de los acontecimientos, las ambigüedades y los problemas lingüísticos filosóficamente no resueltos, irresolubles incluso por mal planteados. ${ }^{58}$

En este sentido, para diversos sectores de la filosofía analítica, esta ya no pretende cimentar el conocimiento, sino describir, para un conjunto específico de humanos, ciertas problemáticas, formulándolas sin una pretensión exhaustivamente exacta, y

\footnotetext{
55 "La analítica rompe con el idealismo filosófico, y en esta óptica es G. E. Moore, quien se ubica dentro de los iniciadores de un llamado en el quehacer filosófico a asumir el método del análisis, ya que según él 'algo llega a ser inteligible cuando es analizado dentro de sus conceptos constitutivos'. Sin duda este planteamiento de Moore da origen a la filosofía analítica" (Baldwin, "Analytical Philosophy" 1, 224. La traducción del inglés es mía.

${ }^{56}$ Para los dos últimos párrafos, ver a Ferrater Mora, Diccionario de filosofía abreviado, 29-30.

${ }^{57}$ Ver a Russell, "On Denoting”; ídem, “The Elements of Ethics”; Gadamer, Verdad y método; Griffin (ed.), The Cambridge Companion to Bertrand Russell.

${ }^{58}$ Mercabá, "Filosofía analítica".
} 
con un propósito muy semejante al de otros saberes humanísticos (historia, crítica literaria, poesía, periodismo, etc.): interactuar, en pie de igualdad con ellos, en la llamada "conversación de Occidente" o "conversación de la humanidad"s9.

En el mismo horizonte se ubica Richard Rorty, neopragmatista, quien a la vez se reivindica como integrante de la filosofía analítica. La define como el empeño de exponerse a la crítica recíproca en este momento caracterizado por la renovación de la lógica y la voluntad de restablecer el diálogo entre la filosofía, el sentido común y la ciencia. Es decir, se trata de la construcción de los inéditos y más felices modos de conversación, superando toda pretensión de objetividad. De esta manera, nos hallamos en la más típica acción comunicativa personal y social, en la cual la conducta humana solo puede valorarse y crecer mediante el diálogo y el reconocimiento mutuo ${ }^{60}$. De la misma manera,

Rorty rechaza la teoría de la verdad como correspondencia del conocimiento humano con esencias eternas, inmutables, que se imponen por sí mismas más allá de cualquier interés personal o social. Él verifica que tal correspondencia solo se da en el campo de nuestras creencias las cuales se fundamentan en hechos que aprehendemos solo desde la fe. Para este análisis Rorty se inspira en varias posturas filosóficas, entre ellas, el ataque al "mito de lo dado" por parte de Sellars. ${ }^{61}$

\section{La ética cristiana: no hay mayor amor que el de aquel que da la vida por sus amigos}

La ética cristiana ${ }^{62}$ como la vivencia de Jesús, el absolutamente otro y alteridad por excelencia, también enriquece mucho la construcción de esta convergencia de la ciencia ética a la que me vengo refiriendo. Habermas está argumentando con gran solidez la urgencia de los valiosos aportes del Evangelio y las grandes religiones a todo tipo de consenso valorativo conductual.

\footnotetext{
${ }^{59}$ Para este párrafo, ver ibíd., Railton, "Analytic Ethics", 1, 220-223. "Russel no creyó que sus opiniones políticas o morales tuvieran una especial autoridad, y nunca sotuvo que su idoneidad como filósofo lo colocara en un lugar superior respecto al análisis ético o social. Él no fue un intérprete de la manifestación histórica del absoluto, ni buscó ser un punto de referencia muy cualificado para determinar cuál era el mejor partido político" (Pigdem, "Bertrand Russell: Moral Philosopher or Unphilosophical Moralist?", 482. La traducción del inglés es mía).

${ }^{60}$ Para este párrafo, ver a Sacchetto, "Filosofia analitica e neopositivismo nei manuali per i licei", 681-693; y Abbagnano, Dizionario di filosofia, 40.

${ }^{61}$ Lord Quinton, "Rorty, Richard”, 822-823. La traducción del inglés es mía.

${ }^{62}$ Ver a Bastianel, Moralità personale nella storia; Curran, The Catholic Moral Tradition Today; Junges, Evento Cristo e açāo humana. Temas fundamentais da ética teológica; McAuliffe, Fundamental Ethics. A Liberationist Approach; Novoa, La urgencia de la ética y el derecho; ídem, Una perspectiva latinoamericana de la teología moral; Keenan (ed.), Catholic Theological Ethics. Past, Present, and Future.
} 
La neutralidad ideológica del poder supremo del Estado democrático, la cual garantiza a cada ciudadano libertades éticas iguales, es incompatible con la generalización política de una cosmovisión secular. Los ciudadanos secularizados, en cuanto se presentan en el papel de ciudadanos, no pueden negar ni a los conceptos religiosos del mundo un potencial verdadero, ni negarles a los conciudadanos creyentes el derecho de convertir aportes con idioma religioso en discusiones públicas. Una cultura política liberal puede esperar hasta de los ciudadanos secularizados que participen en los esfuerzos por traducir aportes relevantes del idioma religioso a un idioma públicamente accesible. ${ }^{63}$

Sin embargo, ¿qué es la ética cristiana? Esta es una forma de comportarse y de existir que emerge de experimentar la vida de una persona: Jesús de Nazaret. Aprehendemos, quienes estamos empeñados en vivirlo, un gozo, una alegría y una plena realización infinitas provenientes de su ser alteridad por excelencia. Lastimosamente, vivimos una sociedad que con frecuencia nos llena de frustraciones, en la que dominan las relaciones egoístas y excluyentes, donde el bienestar integral del otro se ignora sistemáticamente. Asimismo, la indiferencia, la violencia y el odio son comunes en los vínculos interpersonales y sociales, y hacen crecer el hambre, la soledad y la muerte en la humanidad contemporánea. Vienen al caso unas palabras de la madre a su hijo según Máximo Gorki: "No te pido más que una cosa: ¡No hables con la gente sin precaución! Hay que recelar de ella: ¡Todos se odian unos a otros! Viven para la codicia, viven para la envidia. A todos les alegra hacer daño" ${ }^{64}$.

En cambio, Jesús es lo absolutamente otro: es un estilo de conducta humana definitivamente opuesto a lo característico de hoy, y por ello nos llena de una fruición sin par. El Hijo del Hombre es un apasionado por cada congénere, en él no existe la indiferencia sino el infinito compromiso de realizar lo que más brinde plenitud a cada uno. Para él la alegría de cada persona es la suya y su dolor es absolutamente propio $^{65}$. Esto se revela en la capitalidad de la compasión en el Evangelio.

Cuando el Evangelio habla de compasión, este vocablo en la versión del griego de la koiné es $\sigma \pi \lambda \alpha \Upsilon \chi v i \zeta o \mu \alpha 1$, splangnizomai. Esta palabra, en el contexto mediterráneo del siglo primero, significa dolor en lo más profundo de las entrañas. También es un término médico: dolor de parto. Y este es el dolor del Seńor al encontrarse con

\footnotetext{
${ }^{63}$ Habermas y Ratzinger, Entre razón y religión. Dialéctica de la secularización, 32-33. Esta cita es de Habermas.

${ }^{64}$ Gorki, La madre, 47.

65 "En algunos ámbitos de la catolicidad se ha cultivado una cierta visión individualista de la persona, según la cual solo cuenta lo que cada uno es y hace. Sin embargo, a mujeres y hombres los constituye un claro talante relacional. La antropología católica reconoce que el ser humano se forma junto con sus congéneres" (Curran, The Catholic Moral Tradition Today, 99. La traducción del inglés es mía).
} 
el sufrimiento del otro, según diversos relatos evangélicos (Mc 1,41; 6,34; 8,2; 9,22; Mt 9,36; 14,14; 15,32; 18,27; 20,34; y Lc 7,13; 10,33; 15,20) $)^{66}$.

Splangnizomai: Tener compasión, tener piedad. ${ }^{7}$

$\sigma \pi \lambda \alpha \gamma \chi v i \zeta \zeta o \mu \alpha 1:$ compadecerse, tener compasión, tener misericordia. ${ }^{68}$ $\sigma \pi \lambda \alpha \gamma \chi v i \zeta^{\prime} \rho \mu \alpha 1:$ conmoverse, compadecerse. ${ }^{69}$

$\sigma \pi \lambda \alpha \gamma \chi v i \zeta{ }_{0} \mu \alpha 1:$ splangnizomai, sentir que las entrañas anhelan. En sentido figurado, sentir lástima, compadecer, misericordia, mover a misericordia, compasión.

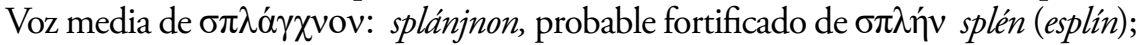
intestino, (plural); en sentido figurado, compasión o lástima, cariño, corazón, entraña, amor entrañable (Mt 9,36). ${ }^{70}$

Jesús sintió compasión: el griego splangnizomai proviene de los nombres que denominan 'entrañas', 'intestinos', 'tripas', como el asiento de las emociones. ${ }^{71}$

Lo más típico de la conducta del profeta de Nazaret es el splangnizomai. Para él, la angustia de cada mujer y hombre es la propia, es un tremendo dolor de parto, ni más ni menos, y es esta vivencia lo lanza a actuar para superar tal angustia. Por ello, frente al hambre, comparte pan (Mc 6,41); ante la enfermedad, cura (Mt 8,6; Lc 7,10; Jn 5,9); y, de cara a la arrogancia de poder y al egoísmo humanos, acoge a los excluidos (Jn 8,7; Mt 11,25) denunciando con valentía los desmanes de los dominadores contra los débiles (Lc 6,24; Mt 20,17-28). E insisto: Jesús constituye la alteridad por antonomasia y lo absolutamente otro de cara a la cotidianidad humana actual y de siempre, quien sin duda nos llena de la más gozosa plenitud existencial.

La fuente de esta ética o moral placentera sin par nace de la vivencia del Mesías, del otro como hermana o hermano siempre igual a él, sujeto de una radical dignidad.

${ }^{66}$ Denyer, Concordancia de las sagradas escrituras: revisión de 1960 de la versión Reina-Valera, 147; Passelecq y Poswick (eds.), Concordanza Pastorale della Bibbia, 235.

${ }^{67}$ Vigini, Vocabolario del Nuovo Testamento Greco-Italiano. Lessico analitico dei verbi, 327. La traducción del italiano es mía. " $\sigma \pi \lambda \alpha \Upsilon \chi v i \zeta \zeta o \mu \alpha ı$ splangnizomai, en los Sinópticos. El verbo figura en el Nuevo Testamento solo en los Sinópticos. En tres parábolas denota actitudes humanas de tener compasión: Mt 18,27, el amo tiene compasión del siervo; Lc 15,20, el padre tiene compasión del hijo pródigo; Lc 10,33, el samaritano tiene compasión del malherido. En todos los casos el término refleja la totalidad de la misericordia divina, a la cual la compasión humana es una respuesta apropiada. En otros lugares de los Sinópticos el verbo tiene significación mesiánica, ya que solo Jesús muestra compasión, como en Mc 1,42; 6,34; 8,2; 9,22; y Mt 14,14; 20,34 (Kittel, Compendio del diccionario teológico del Nuevo Testamento, 1047).

${ }^{68}$ Ortiz, Concordancia manual y diccionario greco-español del Nuevo Testamento, 358.

${ }^{69}$ Pabón Suárez de Urbina, Diccionario griego-español, 541.

${ }^{70}$ Strong, Nueva concordancia exhaustiva de la Biblia: Sección "Diccionario de palabras griegas", 79.

${ }^{71}$ Brown, Fitzmeyer y Murphy (eds.), The New Jerome Biblical Commentary, 650. La traducción del inglés es mía. 
El congénere es fuente de vida y por ello merece todo nuestro cuidado y afecto. Así, el Hijo de María consolida una comunidad de fraternidad y crecimiento maravillosos ${ }^{72}$. Esta dinámica se constituye, por ende, en la valoración positiva fundamental de toda conducta. Tal es el gran aporte del cristianismo a la construcción del mínimo humano que nos urge, sin duda, un aporte de gran crecimiento y enriquecimiento. $Y$ de nuevo, la vida evangélica es gozo y fruición; no hemos venido a la tierra a sufrir y llorar, sino ante todo a ser felices, no de cualquier manera, obvio, sino en la senda de la alteridad.

El propósito capital de la vida cristiana es el ejercicio de la felicidad. Esta es, para Santo Tomás de Aquino, el fin último de la existencia humana ${ }^{73}$. "Estén siempre alegres en el Señor, estén alegres" (Flp 4,4-7); “Dios nos procura todo en abundancia para que lo disfrutemos" (1Tm 6,17), insiste Pablo en sus cartas; "amense unos a otros como yo los he amado, les digo esto para que su alegría sea completa” (Jn 15,11-15) o "sirvan a los demás y serán felices" (Jn 13,12-17) constata Jesús.

La alegría del Evangelio llena el corazón y la vida entera de los que se encuentran con Jesús [...]. Con Jesucristo siempre nace y renace la alegría [...]. El Evangelio [...] invita insistentemente a la alegría [...]. Por donde los discípulos pasaban, había "una gran alegría" (Hch 8,8), y ellos, en medio de la persecución, "se llenaban de gozo" (Hch 13,52) [...] ¿Por qué no entrar también nosotros en ese río de alegría? ${ }^{34}$

En este caminar, el reto es dejarnos invadir por Cristo, dejarnos seducir por él, por su ética, por su vida, y seguir realizándola con toda la plenitud que conlleva. Marchar así implica un camino de conversión permanente al Señor, ya que -como señalo al comienzo de este escrito- el egocentrismo y la alteridad subyacen en lo más hondo de nuestro ser, y se trata de superar el egocentrismo y asumir la alteridad. Esta plenitud de lo humano es Dios mismo, el absoluto de Jesús -madre y padre-, quien lo anima, lo guía, y Cristo lo busca incansablemente en su Espíritu, que actúa para renovarlo y brindarle plenitud, todo de forma permanente.

\footnotetext{
72 "El cuerpo de Cristo encarnado en todas las naciones asume los mejores valores de cada pueblo y país, rechazando la opresión contra cualquier cultura: esto constituye el regalo divino para cada cristiano. Identificarse con el pueblo de Dios es hacer propias sus alegrías y tristezas" (Schlabach, "Breaking Bread: Peace and War”, 373. La traducción del inglés es mía).

73 "La felicidad es el más perfecto de los bienes y, en consecuencia, es el fin último y el mejor" (Santo Tomás de Aquino, Comentario a la Ética a Nicómaco de Aristóteles, Lib. I, IX, 64). "Es entonces razonable que la felicidad sea un don del Dios supremo porque ella es el mejor entre los bienes humanos" (ibíd., Lib. I, XIV, 102). Ver a Pérez Chacal, "La felicidad en Santo Tomás de Aquino".

${ }^{74}$ Francisco, "Exhortación apostólica Evangelii gaudium sobre el anuncio del Evangelio en el mundo actual" $1,3,5$.
} 
Por esto Jesús comunica la plenitud de la persona a la propia persona (GS 22); o sea que Jesús, Dios mismo ${ }^{75}$, es plenitud de humanidad, el absolutamente otro.

En tal estado de fidelidad, quien sigue al Señor, quien lo ha encontrado y vive en familiaridad con él "se encuentra a sí mismo renovado en profundidad, cambiado desde adentro, realizando una vida nueva, aquella que se apela con términos como renacimiento, regeneración ${ }^{76}$ etc." ${ }^{77}$, rebosante de plenitud y de fruición sin par. La novedad de vida y de fe del creyente madura cuando, al "sentir y gustar internamente" 78 la particular vida y muerte de Jesús, aprehende no solo al vencedor de la defunción que existe y nos vivifica de tantas maneras, sino que Cristo lo hace capaz de una vida humana auténtica y plena. ${ }^{79}$ De la misma manera, el Hijo del Hombre comunica a su discípulo una mente y un corazón nuevos, capacitándolo para realizar en la vivencia de la donación total del Mesías, el sentido humano de vivir sobre la tierra y el sentido pleno de su propia existencia ${ }^{80}$.

El principio explicativo de la práctica de Jesús es su enraizamiento en el amor de Dios, madre y padre, quien crea una perspectiva de liberación y de amor. El Hijo del Hombre se encuentra libre frente a los determinismos socioculturales y religiosos de su tiempo, para dejarse animar únicamente por la ternura de Dios y su Reinado. Su comportamiento es una praxis de liberación y de amor. Esta praxis afincada en el afecto a su absoluto se cristaliza en el camino de totalidad para el seguidor de Cristo ${ }^{81}$. Jesús, hombre hasta lo último, y consiguientemente Dios por excelencia, absolutamente otro, splangnizomai por antonomasia, camina con nosotros y por ende nunca nos obliga a nada; rechaza para sí y su seguimiento la creencia de sentirse poseedor de la

75 "En el Nuevo Testamento el amor a Dios y a la persona constituyen una sola confluencia. El llamado Juicio Final en la escena de Mt 25 certifica cómo todo lo que hacemos a las hermanas y hermanos más relegados, lo hacemos a Dios mismo. Los evangelios sinópticos enfatizan el afecto por los enemigos (Mt 5,43-47; Lc 6,27-36). La primera Carta de Juan 4,20-21 nos interpela verificando que quien dice que ama a Dios a quien no ve y no ama a su hermano a quien ve es un mentiroso" (Curran, The Catholic Moral Tradition Today, 73. La traducción del inglés es mía).

76 "Términos que aparecen sobre todo en los escritos paulinos, los cuales evocan la misma experiencia de apóstol de Tarso" (Bastianel, Moralità personale nella storia, 76. La traducción del italiano es mía).

77 Ibíd., 77. La traducción del italiano es mía.

${ }^{78}$ San Ignacio de Loyola, Ejercicios espirituales. Principio y fundamento 23.

79 "En la Pascua cristiana experimentamos que la bondad prevalece sobre todo, que la muerte y vida de Jesús no es solo buena y correcta sino que su testimonio gobernará y sus esfuerzos triunfarán 'en el fin de los tiempos'. Toda esta dinámica crística es una muy poderosa fuente de esperanza para hoy y el porvenir" (McAuliffe, Fundamental Ethics, 145. La traducción del inglés es mía).

${ }^{80}$ Para los últimos tres párrafos, ver a Bastianel, Moralità personale nella storia, 76-79.

${ }^{81}$ Para este párrafo, ver a Junges, Evento Cristo e açāo humana, 110. 
verdad única y completa que urge imponer a como dé lugar; todo lo contrario, como dice el papa Francisco ${ }^{82}$.

\section{El aporte al consenso moral mínimo del diálogo entre las éticas filosófica y teológica cristiana}

En el recorrido que hemos hecho por las éticas filosóficas actuales y por la ética teológica cristiana podemos verificar entre todas ellas una confluencia común: la alteridad. Y esta aprehende tal confluencia en la conformación de vida plena como splangnizomai, al ponernos en los zapatos del otro, al superar la indiferencia ante el dolor hermano, al dar vía dejándonos tocar por el congénere, creciendo integral y recíprocamente en el reconocimiento mutuo, enriqueciéndonos continuamente de forma gratuita y generosa, evitando siempre todo tipo de exclusión. Al recorrer esta senda constituimos una auténtica convivencia o comunidad humana al tenor del reino de los fines kantiano, de la realización efectiva habermasiana de la conciencia de lo que falta de lo que clama al cielo: la solidaridad.

Asimismo, hacemos real el absoluto de la dignidad humana, la solidaridad y la justicia en el tono de las filosofías pragmatista y del lenguaje, como lo verifica de forma sugerente Richard Rorty: lo único que cuenta es el otro. Tal alteridad sucede en el devenir de la palabra, como lo argumenta la analítica, ya que somos lenguaje y este solo acaece en la relación social; relación que sin la efectividad de los hechos de los actos se disuelve al tenor de pragmatismo; otreidad que también acaece en la hermenéutica intersubjetiva de la valoración moral, único camino que garantiza la permanente construcción de las múltiples morales y los mínimos éticos insoslayables en reconocimiento mutuo en plena libertad; reconocimiento constitutivo de nuestro devenir valorativo conductual halado por el desenvolvimiento de la felicidad y el placer para el mayor número de personas, como lo constata el utilitarismo. Se trata de una otreidad en la que converge el compromiso neocontractualista con la equidad y la igualdad de oportunidades.

En esta confluencia de alteridad converge también la posmodernidad, al certificar el requerimiento de la superación de los metarrelatos impuestos y ajenos al devenir humano, a través de la construcción de humanidad y eticidad mediante la conversación y el diálogo, que reivindica toda la frescura y plenitud de la cotidianidad personal y social, lo único auténticamente vital.

Emerge entonces, con toda su fuerza, este consenso mínimo de la alteridad entre la ética teológica cristiana y diversas escuelas ético-filosóficas. Y al ser

\footnotetext{
${ }^{82}$ Francisco, "Carta al periodista italiano Eugenio Scalfari del periódico La Repubblica".
} 
mínimo, simultáneamente es de gran alcance, ya que a lo largo de este escrito he venido argumentando la vasta riqueza de la otreidad, así como el alto nivel de realización humana que ella nos proporciona.

Sin duda nos encontramos ante una convergencia que, además de salvarnos de la anarquía, la anomía y sus terribles consecuencias, marca una cota muy alta para la realización de mujeres y hombres. Correlato de esta conjunción es la vigencia de las diferencias de todas las escuelas que concursan, las cuales -como paso a señalarlo- no limitan nuestro consenso mínimo: antes bien, lo potencializan pues esta diversidad no es excluyente, sino todo lo opuesto.

El comportamiento humano debe tener en cuenta, en su desenvolvimiento, las consecuencias prácticas que produce y producirá. "Obras son amores y no buenas razones", reza el adagio castellano; "por sus obras los conocerán" (Mt 7,15-20) confirma el Evangelio. Por ello, la ética ante todo consiste en conductas concretas, que deben velar por la conquista del bien en esta concreción hoy y en el futuro, ya que personas y sociedades siempre están proyectadas al porvenir. Consiguientemente, la moral debe velar por la eficacia en la realización del propósito que le es propio mediante su aplicación práctica; de lo contrario es irrelevante, no existe. $\mathrm{Y}$ en este devenir -por supuesto- hay que priorizar los hechos sobre las teorías especulativas. Este es el gran aporte del pragmatismo a la alteridad, no para negarla, sino para hacerla florecer.

La persona es relación y por ende comunicación. Este hecho la fuente de la sobrevivencia y del crecimiento de la humanidad. En la absoluta soledad, sin el otro y sin interactuar con él, estoy muerto. Comunicarnos, o sea, poner en común todo lo que somos y tenemos nos engendra a la vida. Esta capacidad comunicacional que nos hace existir es el ámbito más humano, cuyo fin es construir el mínimo ético válido para todas las personas, sin el cual nos suicidamos. Poner en común es colocar sobre la mesa todos nuestros intereses y confrontarlos recíprocamente para encontrar el punto de convergencia valorativo conductual que nos asegure la convivencia pacífica y por ello incluyente. De esta manera garantizamos la alegría sin par de vivir, manteniendo nuestras diferencias morales y de todo orden. Esto es alteridad por excelencia y cristaliza su gran aporte a la ética discursiva.

Somos palabra, nos constituye el lenguaje; nuestro saber, cotidianidad y existencia son locución. El giro lingüístico revela que el esencialismo aristotélico, el mundo noumenal o la metafísica positivista no nos tocan: son ficciones superadas que en ninguna modalidad trasmite el habla. Por ello, como lo dado ha quedado atrás, la ciencia de la sabiduría y, por ende, la filosofía ética, es fruto de la conversación, la crítica y la reflexión, según Richard Rorty. Solo en la praxis locutoria, interpersonal por antonomasia, podemos construir el saber, la valoración comportamental, la totalidad 
de la existencia. Actos de habla que se hallan en la raíz de la alteridad: he ahí el gran aporte de la analítica a nuestro consenso de la otreidad.

El capricho egoísta y las satisfacciones individualistas no pueden ser el criterio ético fundamental, ya que de esta manera se elimina sistemáticamente al otro y permanece tan solo el imperio del narcisismo. Por desgracia, tanto ayer como hoy amplios sectores de la humanidad han apostado y siguen apostando a dicho imperio. El mencionado criterio debe garantizar a los seres humanos vida, realización integral y ausencia de cualquier exclusión. En este orden de ideas, tal criterio solo puede ser el absoluto de la persona y de su dignidad. Y es Kant quien estructura y da a luz este absoluto, aporte capital a nuestra confluencia moral básica. La dignidad de la persona humana y sus correlatos de justicia y solidaridad conforman los valores éticos inalienables, cúspide total de toda moral femenina y masculina. Ya he argumentado cómo estos valores constituyen el corazón de la alteridad.

En el devenir personal y social, lo que tiene sentido y por lo que hay que jugársela es la vivencia de lo cotidiano, lo vital, lo existencial, lo estético, lo afectivo. Tal vivencia cobra toda su relevancia en el reconocimiento mutuo y la edificación de comunidades inclusivas, donde el eje es el congénere, al decir de Vattimo y Rorty. Por ello se impone la superación de los metarrelatos y la metafísica, parafernalias especulativas abstractas y estrategias de poder y dominación que nada dicen ni significan al diario desenvolvimiento de mujeres y hombres. Según Vattimo, se trata de eliminar la ontología objetiva y cualquier tipo de fundamento que no esté relacionado con el amor y la solidaridad. Esto es la posmodernidad y su aporte a nuestro consenso mínimo. La alegría del otro es mi alegría, el dolor del congénere -de mi hermana y hermanoes el mío, un hondo dolor de parto. Si todos nos permitiéramos esta vivencia, en la tierra no habría hambre, ni guerras, ni excluidos, y nuestra convivencia sería mucho más estimulante. El splangnízomai es la entrega fascinante, generosa y gratuita a los demás, el gozo sin par, el cenit de una vida auténtica. Practicar y comunicar tal camino es enteramente ético y constituye un nivel elevado de plena humanidad y alteridad.

Este es un aporte de la ética teológica cristiana a nuestra convergencia moral. Este consenso mínimo no puede tener una confesión espiritual institucional, pues nos encontramos en medio de una humanidad pluricultural y plurirreligiosa. Ello no obsta para que nos sea legítimo proponer el maravilloso camino de Jesús, en plena libertad y sin imposiciones de ningún tipo, como él lo hacía en su vida terrena: "Si quieres, ven y sígueme" (Mt 19,21). 


\section{Bibliografía}

Allen, Anita. The New Ethics. New York: Miramax Books, 2004.

Abbagnano, Nicola. Dizionario di filosofía. Milano: UTET, 2012.

Apel, Karl-Otto. Paradigmas de filosofía primera. Madrid: Prometeo, 2013.

Baldwin, Thomas. "Analytical Philosophy". En The Shorter Routledge Encyclopedia of Philosophy, editado por Edward Craig, 13-14. London: Routledge, 2005.

Bastianel, Sergio. Moralità personale nella storia. Roma: Pontificia Università Gregoriana, 2008.

Benedicto XVI. "Encíclica Caritas in veritate sobre el desarrollo humano integral en la caridad y en la verdad (2011)". Vatican, http://w2.vatican.va/content/ benedict-xvi/es/encyclicals/documents/hf_ben-xvi_enc_20090629_caritas-inveritate.html (consultado el 5 de agosto de 2016).

Braidotti, Rosi. "Nomadic Ethics". En The Cambrige Companion to Deleuze, editado por Daniel W. Smith y Henry Sumers-Hall, 170-196. Cambridge (U. K.): Cambridge University Press, 2012.

Brown, Raymond E., Joseph A. Fitzmeyer y Roland E. Murphy (eds.). The New Jerome Biblical Commentary. Englewood (NJ): Prentice Hall-Pierson, 1990.

Camps, Victoria. Historia de la ética. 3 vols. Barcelona: Crítica, 2009.

Camps, Victoria, Osvaldo Guariglia y Fernando Salmerón. Concepciones de la ética. Madrid: Trotta, 1992.

Chiavacci, Enrico. Teologia morale fondamentale. Assisi, Italia: Citadella Editrice, 2007.

CINEP. Poder y violencia en Colombia. Bogotá: Cinep, 2015.

Compagnoni, Francesco. "Ética”. En Diccionario teológico enciclopédico, dirigido por Luciano Pacomio, 344-345. Estella (Navarra): Verbo Divino, 1995.

Copleston, Frederick. Historia de la filosofía. 9 vols. Barcelona: Ariel, 2011.

Coromines, Joan. Breve diccionario etimológico de la lengua castellana. Madrid: Gredos, 2008.

Cortina, Adela. Ética minima. Introducción a la filosofia práctica. Madrid: Tecnos, 2006.

Curran, Charles. The Catholic Moral Tradition Today. Washington D. C.: Georgetown University Press, 2000.

Craig, Edward (ed.). Routledge Encyclopedia of Philosophy. 9 vols. London: Routledge, 1998. 
Deeds, Elizabeth. "Postmodernism and Political Philosophy". En Routledge Encyclopedia of Philosophy, editado por Edward Craig, Vol. 7, 589-590. London: Routledge, 1998.

Denyer, C. P. Concordancia de las sagradas escrituras: revisión de 1960 de la versión Reina-Valera (3. ${ }^{a}$ ed.). Miami: Caribe, 1974.

Dostal, Robert J. The Cambridge Companion to Gadamer. New York City: Cambridge University Press, 2002.

Downie, R. S. "Evil, human". En The Oxford Companion to Philosophy, editado por Ted Honderick, 470. New York: Oxford University Press, 2005.

. "Kantian Ethics". En The Oxford Companion to Philosophy, editado por Ted Honderick. New York: Oxford University Press, 2005.

Durken, Daniel (ed.). New Collegeville Bible Commentary. New Testament. Collegeville (MN): Liturgical Press, 2008.

Farmer, William (ed.). Comentario biblico internacional. Estella (Navarra): Verbo Divino, 2005.

Ferrater Mora, José. Diccionario de filosofía. 4 vols. Barcelona: Ariel, 2001.

. Diccionario de filosofía abreviado. Barcelona: Edhasa, 2008.

. "Pragmatismo". En Diccionario de filosofia, por J. Ferrater Mora, Tomo III, 2872. Barcelona: Ariel, 2001.

Francisco. "Audiencia general, Roma, 5 de junio de 2013". Vatican, https:// w2.vatican.va/content/francesco/es/audiences/2013/documents/papa-francesco_20130605_udienza-generale.html (consultado el 5 de agosto de 2016). . "Carta al periodista italiano Eugenio Scalfari del periódico La Repubblica". Vatican, https:/w2.vatican.va/content/francesco/es/letters/2013/documents/ papa-francesco_20130911_eugenio-scalfari.html (consultado el 5 de agosto de 2016).

- "Discurso a los participantes en el Encuentro Mundial de Movimientos Populares, 28 de octubre de 2014". Vatican, https://w2.vatican.va/content/francesco/ es/speeches/2014/october/documents/papa-francesco_20141028_incontromondiale-movimenti-popolari.html (consultado el 5 de agosto de 2016).

. "Entrevista del Papa con Scalfari". Religión digital, 1 de octubre de 2013, http://www.periodistadigital.com/religion/vaticano/2013/10/01/entrevista-delpapa-con-scalfari-iglesia-religion-francisco-dios-jesus-jesuitas.shtml (consultado el 5 de agosto de 2016). 
- "Exhortación apostólica Evangelii gaudium sobre el anuncio del Evangelio en el mundo actual (2013)". Vatican, http://w2.vatican.va/content/francesco/es/ apost_exhortations/documents/papa-francesco_esortazione-ap_20131124_ evangelii-gaudium.html (consultado el 5 de agosto de 2016).

. "Homilía en Lampedusa. Campo de deportes, 8 de julio de 2013”. Vatican, https://w2.vatican.va/content/francesco/es/homilies/2013/documents/papafrancesco_20130708_omelia-lampedusa.html (consultado el 5 de agosto de 2016).

. "II Encuentro Mundial de los Movimientos Populares con el papa Francisco, Santa Cruz de la Sierra, Bolivia, 7-9 de julio de 2015”. Agenda latinoamericana mundial, http://latinoamericana.org/2016/info/docs/CartillaMovsPopularesPapaFranciscoBolivia.pdf (consultado el 5 de agosto de 2016).

Gadamer, George. Verdad y método. Buenos Aires: Paidós, 2005.

Gorki, Máximo. La madre. Madrid: Sopena, 2004.

Griffin, Nicholas (ed.). The Cambridge Companion to Bertrand Russell. New York (NY): The Cambridge University Press, 2003.

Guyer, Paul. "Kant Immanuel”. En Routledge Encyclopedia of Philosophy, editado por Edward Craig, Vol 5, 189. London: Routledge, 1998.

Habermas, Jürgen. Carta al Papa (la conciencia de lo que falta). Barcelona: Paidós, 2009. . Facticidad y validez. Madrid: Trotta, 2010. . Teoría de la acción comunicativa. Buenos Aires: Taurus, 2003.

Habermas, Jürgen y Joseph Ratzinger. Entre razón y religión. Dialéctica de la secularización. México: Fondo de Cultura Económica, 2008.

Hauerwas, Stanley y Samuel Wells (eds.). The Blackwell Companion to Christian Ethics. Hoboken (NJ): Blackwell Publishing, 2006.

Heidegger, Martin. Ser y tiempo. México: Fondo de Cultura Económica, 2003.

Hepburn, R. W. "Egoism and Altruism". En The Oxford Companion to Philosophy, editado por Ted Honderick, 236-237. New York: Oxford University Press, 2005.

Hernández, Alberto y otros. Ética actual y profesional. Lecturas para la convivencia global en el siglo XXI. México: Thomson Learning, 2006.

Honderick, Ted (ed.). The Oxford Companion to Philosophy. New York: Oxford University Press, 2005. 
James, William. Pragmatism: A New Name for Some Old Ways of Thinking. Minneapolis (MN): Filiquarian Publishing, 2007.

Jozami, Yezmin. "Filosofía posmoderna”. Scribd, http://es.scribd.com/doc/54955620/ Filosofia-posmoderna\#scribd (consultado el 5 de agosto de 2016).

Junges, José Roque. Evento Cristo e açāo humana. Temas fundamentais da ética teológica. Sāo Leopoldo (R.S): Unisinos, 2002.

Kant, Emanuel. Fundamentación de la metafisica de las costumbres. Barcelona: Ariel, 1999.

Keenan, James F. (ed.). Catholic Theological Ethics. Past, Present, and Future. Maryknoll (NY): Orbis Books, 2011.

Kittel, Gerhard y Gerhard Friedrich. Compendio del diccionario teológico del Nuevo Testamento. Grand Rapids (MI): Desafío, 2002.

Küng, Hans y otros. Ética mundial. Una guía para descubrir los valores que todos tenemos en común. Bogotá: El Tiempo, 2010.

Lévinas, Emanuel. El tiempo y el otro. Barcelona: Paidós, 1993.

Levoratti, Armando (dir.). Comentario bíblico latinoamericano. 3 vols. Estella (Navarra): Verbo Divino, 2003.

Lord Quinton. "Rorty, Richard". En The Oxford Companion to Philosophy, editado por Ted Honderick, 822-823. New York: Oxford University Press.

Lyotard, Jean-Francois. La condición posmoderna. Informe sobre el saber. Barcelona: Cátedra, 1989. . La Posmodernidad. Barcelona: Gedisa, 2012.

McAuliffe, Patricia. Fundamental Ethics. A Liberationist Approach. Washington D. C.: Georgetown University Press. 2000.

Mercabá. "Filosofía analítica”. Mercabá, www.mercaba.org/DicFI/A/analitica_filosofia. htm (consultado el 5 de agosto de 2016).

Misak, Cheryl (ed.). The Cambridge Companion to Peirce. New York (NY): Cambridge University Press, 2004.

Noddings, Nel. Caring: A Feminine Approach to Ethics \& Moral Education. Berkely-Los Angeles-London, The University of California Press, 2003.

Norris, Christopher. "Post-modernism". En The Oxford Companion to Philosophy, editado por Ted Honderick, 745. New York: Oxford University Press. 
Novoa, Carlos. La ciencia desafía la fe. Bogotá: Pontificia Universidad Javeriana, Facultad de Teología, 2016.

. La urgencia de la ética y el derecho. Bogotá: Pontificia Universidad Javeriana, Facultad de Teología, 2012.

- Una perspectiva latinoamericana de la teología moral. Bogotá: Pontificia Universidad Javeriana, Facultad de Teología, 2009.

O’Neill, Onora, “Kantian Ethics”. En The Shorter Routledge Encyclopedia of Philosophy, editado por Edward Craig, 507-510. London: Routledge, 2005.

Ortiz, Pedro. Concordancia manual y diccionario greco-español del Nuevo Testamento (3. ${ }^{a}$ ed.). Madrid: Sociedades Bíblicas Unidas, 2006.

Pabón Suárez de Urbina, José María. Diccionario griego-español. Barcelona: Vox, 1996.

Passelecq, Georges y Ferdinand Poswick (eds.). Concordanza pastorale della Bibbia. Nuova Edizione. Bologna: Edizioni Dehoniane Bologna, EDB, 2012.

Pérez Chacal, Jorge. "La felicidad en Santo Tomás de Aquino". Círculo de Estudios Tomistas Universidad Católica Cecilio Acosta, http://tomismounica.blogspot. es/1265287777/la-felicidad-en-tom-s-de-aquino-jorge-p-rez-chacal-/ (consultado el 10 de enero de 2017).

Pierce, Charles S. Pragmatism as a Principle and Method of Right Thinking. The 1903 Harvard Lectures on Pragmatism. New York (NY): State University of New York Press, 1997.

Pigdem, Charles. "Bertrand Russell: Moral Philosopher or Unphilosophical Moralist?" En The Cambridge Companion to Bertrand Russell, editado por Nicholas Griffin, 475-506. New York (NY): The Cambridge University Press, 2003.

Pihlström, Sami. "Peirce's Place in the Pragmatist Tradition”. En The Cambridge Companion to Peirce, editado por Cheryl Misak, 27-57. New York (NY): Cambridge University Press, 2004.

Railton, Peter. "Analytic Ethics". En Routledge Encyclopedia of Philosophy, editado por Edward Craig, Vol. 1, 220-223. London: Routledge, 1998.

Rescher, Nicholas. "Pragmatism". En The Oxford Companion to Philosophy, editado por Ted Honderick, 747-751. New York: Oxford University Press, 2005.

Rorty, Richard. Filosofía y futuro. Barcelona: Gedisa, 2009. . "Pragmatism". En The Shorter Routledge Encyclopedia of Philosophy, editado por Edward Craig, Vol. 7, 838-843. London: Routledge, 2005. 
. Una ética para laicos. Buenos Aires: Katz, 2009.

Rorty, Richard y Gianni Vattimo. El futuro de la religión. Barcelona: Paidós, 2006.

Rorty, Richard y Jürgen Habermas. Sobre la verdad: ¿validez universal o justificación? Buenos Aires: Amorrortu, 2008.

Russell, Bertrand. “On Denoting”. Mind. New Series Vol. 14, No. 56 (1905): 479-493. . "The Elements of Ethics". En Philosophical Essays, por B. Russell. London: Routledge, 1966. Disponible en: Fair Use Repository, http://fair-use.org/ bertrand-russell/the-elements-of-ethics (consultado el 20 de enero de 2017).

Sacchetto, Mauro. "Filosofia analitica e neopositivismo nei manuali per i licei". Rivista di storia della filosofia (1984-) Vol. 51, No. 3 (1996): 681-693.

San Ignacio de Loyola. Ejercicios espirituales. Principios y fundamento. Madrid: Biblioteca de Autores Cristianos, 2008.

Santo Tomás de Aquino. Comentario a la Ética a Nicómaco de Aristóteles. Pamplona: Eunsa, 2000.

Savater, Fernando. Etica para Amador. Barcelona: Ariel, 2004.

Schlabach, Gerald. "Breaking Bread: Peace and War". En The Blackwell Companion to Christian Ethics, editado por Stanley Hauerwas y Samuel Wells, Capítulo 27. Hoboken (NJ): Blackwell Publishing, 2006.

Singer, Peter. Compendio de ética. Madrid: Alianza, 1995.

Smith, Daniel W. y Henry Sumers-Hall (eds.). The Cambrige Companion to Deleuze. Cambridge (U.K.): Cambridge University Press, 2012.

Strong, James. Nueva concordancia exhaustiva de la Biblia. Miami: Editorial Caribe, 2002.

Tiles, J. E. "Pragmatism in Ethics". En Routledge Encyclopedia of Philosophy, editado por Edward Craig, Vol. 7, 640-644. London: Routledge, 1998.

Vattimo, Gianni. Adiós a la verdad. Barcelona: Gedisa, 2010. . Creer que se cree. Barcelona: Paidós, 1996.

Velilla, Marco. La ética y la defensa de lo público. Un camino para la construcción de la solidaridad y la responsabilidad colectiva. Bogotá: Gestión, 2000.

Vigini, Giuliano. Vocabolario del Nuovo Testamento Greco-Italiano. Lessico analitico dei verbi. Milano: Paoline Editoriale Libri, 2010.

Zubiri, Xavier. Sobre el hombre. Madrid: Alianza, 1986. 